\title{
PRESENTACIÓN
}

\section{ÚlTIMA DÉCADA HACIA UNA NUEVA ÉPOCA}

A partir de la próxima entrega de la Revista Última Década, correspondiente al volumen 39 del segundo semestre 2013, comenzará una nueva época en la edición de la revista.

Luego de veinte años de publicación ininterrumpida por parte de del Centro de Estudios Sociales CIDPA de Valparaíso, la gestión académica y editorial, publicación y difusión de la Revista Última Década pasará a ser responsabilidad de un consorcio de instituciones académicas agrupadas en el Proyecto Anillo de Investigación en Ciencias Sociales "Juventudes. Transformaciones socioeconómicas, sociopolíticas y socioculturales de las y los jóvenes en el Chile contemporáneo», proyecto de investigación financiado por Conicyt (www.proyectojuventudes.cl).

Proyecto asociativo que busca abordar, a través de la investigación sistemática, las transformaciones sociales, politicas y culturales que vive la sociedad chilena, y los modos como las y los sujetos jóvenes se despliegan en estas nuevas condiciones estructurales y subjetivas, con énfasis en tres esferas de estos despliegues juveniles: una socioeconómica, una sociopolitica y una sociocultural. El eje central de este Proyecto de Anillo Juventudes es la producción de conocimiento a través de la investigación.

Esta iniciativa también se propone impulsar la creación de una red de investigación, formación e intercambio académico en temas de juventud, que tenga como objetivo consolidar el tema juvenil como 
campo aplicado de investigación para las ciencias sociales de nuestro país, y promover instrumentos de difusión y transferencia del conocimiento acumulado en juventud a instancias públicas y privadas.

El proyecto se organiza en torno a un equipo de once investigadores, con basta trayectoria en temáticas sobre juventudes, y nueve instituciones públicas y privadas de diversas regiones: Universidad de Valparaíso, Centro de Estudios Sociales CIDPA, Universidad de Chile, Universidad Católica Silva Henriquez, Universidad Católica del Maule, Centro de Estudios Socioculturales (CESC), Universidad del Desarrollo, Universidad de Concepción y Universidad de Magallanes.

La motivación y propósito fundamental de este cambio en la revista se orienta hacia su fortalecimiento como publicación periódica y amplitud en su difusión, en orden a contribuir también en la consolidación del campo de investigación en estudios de juventudes y su difusión. Para ello pretendemos aumentar los volúmenes publicados por año, renovar las instancias editoriales y propender a nuevas indexaciones internacionales de la revista.

Conscientes que esta nueva etapa de la Revista Última Década se nos presenta como un bonito desafio, en el afán de proyectar y visibilizar cada vez más la producción de conocimientos en el campo de juventudes, desafio del cual nos interesa dar cuenta; y a su vez, cerrar una larga etapa de largas dos décadas, en ningún caso con nostalgia, sino que con gran satisfacción por lo que hemos logrado alcanzar como CIDPA con la revista: en su continuidad, calidad, reconocimiento y confianza de parte de la comunidad de investigadores en materias de juventud.

EL DIRECTOR

VALPARAÍSO (CHILE), JULIO DE 2013 